\title{
Passive soil heating using an inexpensive infrared mirror design - a proof of concept
}

\author{
C. Rasmussen ${ }^{1}$, R. E. Gallery ${ }^{2,3}$, and J. S. Fehmi ${ }^{2}$ \\ ${ }^{1}$ Department of Soil, Water and Environmental Science, The University of Arizona, Tucson, AZ, USA \\ ${ }^{2}$ School of Natural Resources and the Environment, The University of Arizona, Tucson, AZ, USA \\ ${ }^{3}$ Department of Ecology and Evolutionary Biology, The University of Arizona,Tucson, AZ, USA \\ Correspondence to: C. Rasmussen (crasmuss@ cals.arizona.edu)
}

Received: 3 April 2015 - Published in SOIL Discuss.: 11 May 2015

Revised: 28 August 2015 - Accepted: 8 September 2015 - Published: 21 September 2015

\begin{abstract}
There is a need to understand the soil system response to warming in order to model the soil process response to predicted climate change. Current methods for soil warming include expensive and difficult to implement active and passive techniques. Here we test a simple, inexpensive in situ passive soil heating approach, based on easy to construct infrared mirrors that do not require automation or enclosures. The infrared mirrors consisted of $61 \times 61 \mathrm{~cm}$ glass panels coated with infrared reflecting film. The mirrors as constructed are effective for soil heating in environments typified by an open vegetation canopy. Mirror tests were performed on three soils of varying texture, organic matter content, and heat capacity in a warm semi-arid environment. Results indicated that the infrared mirrors yielded significant heating and drying of soil surface and shallow subsurface relative to unwarmed control treatments, and that warming and drying effects were soil specific with greater potential warming on soils with lower volumetric heat capacity. Partial shading from the mirror frame did produce periods of relative cooling at specific times of the day but overall the mirrors yielded a net soil warming. The results demonstrate proof of concept that the infrared mirrors may be used to passively heat the near soil surface, providing an inexpensive, low-maintenance alternative to other passive and active soil heating technologies.
\end{abstract}

\section{Introduction}

Climate change and warming present significant challenges to understanding future ecosystem response, function, and management. The most recent projections suggest up to a $5^{\circ} \mathrm{C}$ warming by the end of this century, with mean winter and summer warmings of 3.8 and $3.3^{\circ} \mathrm{C}$, respectively (IPCC, 2014). Given these projections, there is a pressing need to understand the response of soil systems to warming, particularly changes in soil-water and -energy budgets, and soil biogeochemical processes such as carbon and nitrogen cycling. Experimental methods for soil and ecosystem warming include temperature-controlled environments in laboratory and greenhouse settings, moving intact soil cores across natural environmental gradients, and heating of soils in situ using various active and passive approaches (Aronson and McNulty, 2009). All of these methods have their shortcomings, e.g., extrapolating results from controlled environments to the field, requirement of aboveground enclosures for passive in situ soil heating, and equipment and operational costs associated with active in situ heating. Currently, an inexpensive and effective alternative for in situ soil heating that does not require an aboveground enclosure is lacking.

Soil and ecosystem heating methods vary widely and have been reviewed in detail in Rustad et al. (2001), Shaver et al. (2000) and Aronson and McNulty (2009). Here we highlight several of the main passive and active methods used in previous field studies as context for the approach tested in this work. Many studies apply active heating methods such as infrared heaters (Harte et al., 1995), cables buried in the soil (Peterjohn et al., 1993), with more recent approaches including a combination of steam injection and passive aboveground enclosures (Hanson et al., 2011). Active methods effectively heat above- and below-ground systems with significant changes observed as a result of heat- 
ing in plant species composition, soil respiration, and soilwater content (Shaver et al., 2000). However, these methods are expensive in terms of equipment setup, operational costs and energy consumption, and require proximity and access to electricity. Passive methods generally include open top chambers and greenhouses placed over mesocosm plots in the field (Kennedy, 1995); however, these approaches exclude and minimize the turbulent transfer of air, energy and water vapor, and the movement of mass (e.g., surface runoff and sediment) into and out of the experimental enclosure. Another passive heating approach consists of nighttime trapping of longwave radiation from the soil with an infrared (IR) reflective sheet above the soil surface that effectively warms the soil overnight (Beier et al., 2004). However, this requires an automated system to lower the IR sheet over the soil surface in the evening and to raise the IR sheet in the morning.

Here we present a simple, inexpensive in situ passive soil heating approach based on easy to construct IR mirrors that do not require automation or enclosures. The objective of this work was to empirically test the efficacy of these mirrors for heating the soil surface and shallow subsoil under field climate conditions.

\section{Materials and methods}

\subsection{Infrared mirror design}

The infrared mirrors consisted of $61 \times 61 \mathrm{~cm}$ glass panels mounted in a $5 \times 5 \mathrm{~cm}$ redwood board frame (Fig. 1). The size of the mirrors were limited to relatively small glass panels for stability and ease of transfer for this proof-of-concept study, but future applications could implement larger glass panels for more permanent installations. The glass panels were mounted in the frame at a height of $15 \mathrm{~cm}$ above the ground surface; with the $5 \times 5$ redwood frame this leaves an air gap of $10 \mathrm{~cm}$ between the bottom of the frame and the ground to allow for air flow and mixing around the base of the panel. The panel glass consisted of common double-strength window glass $3 \mathrm{~mm}$ thick. The side of the glass away from the plot was covered with Gila Titanium heat-control window film (Eastman Chemical Performance Films Division, Gila Film Products, St. Louis, MO, USA). The frames in the field were mounted facing true south, tilted back $10^{\circ}$ from vertical (top of frame tilts away from the plot), and secured with metal t-posts. The glass absorbs ultraviolet light and the film reflects up to $72 \%$ of incoming longwave radiation towards the soil surface according to manufacturer specifications.

\subsection{Field experiments}

The mirrors were tested using a series of field experiments designed to quantify the effect of mirrors on surface and shallow subsurface soil temperature. The experiments consisted of a set of initial field trials followed by a larger-scale test with multiple replicated plots on different soil types. The size of the mirrors is best suited to heating soil in low-stature ecosystems, making them ideal for grassland, short scrub, tundra, and agriculture studies.

\subsubsection{Initial field trials}

Initial field trials were carried out at the Karsten Turfgrass Research Facility located at the University of Arizona Campus Agricultural Center (CAC) in Tucson, AZ, at $32^{\circ} 16^{\prime} 51.77^{\prime \prime} \mathrm{N}, 110^{\circ} 56^{\prime} 13.14^{\prime \prime} \mathrm{W}$, at an elevation of $715 \mathrm{~m}$ a.s.l. The average climate at this location includes a mean annual air temperature of $22.4^{\circ} \mathrm{C}$, mean annual potential evapotranspiration of $1945 \mathrm{~mm} \mathrm{yr}^{-1}$, and mean annual precipitation of $275 \mathrm{~mm} \mathrm{yr}^{-1}$ characterized by a bimodal precipitation regime where $\sim 50 \%$ of precipitation derives from cool winter rains and $\sim 50 \%$ arrives during the summer as part of the North American monsoon, with warm dry periods in the spring and fall. Meteorological data for 2013, the year of observation, fell within climatological norms with a mean temperature of $20.4^{\circ} \mathrm{C}$, potential evapotranspiration of $1933 \mathrm{~mm}$, and annual precipitation of $190 \mathrm{~mm}$. Meteorological data were measured hourly at the CAC using a weather station managed as part of the Arizona Meteorological Network following standard techniques. The station is $<0.5 \mathrm{~km}$ from the study site and data are freely available online (AZMET, 2013, http://ag.arizona.edu/azmet/). The soil at the study area was classified as a coarseloamy over skeletal, mixed, superactive, calcareous, hyperthermic Typic Torrifluvent (http://websoilsurvey.sc.egov. usda.gov/App/WebSoilSurvey.aspx), with a fine sandy loam surface soil that contains 4-7\% clay based on hand texturing, and $<0.5 \%$ organic matter. The parent material was granitic alluvium from the Rillito River and associated local drainages.

The mirrors were placed in an area free of vegetation and groundcover to facilitate direct heating of the soil surface. The initial mirror array consisted of one replicate of three mirrors facing south; the central mirror facing due south, with a mirror on each side at an angle of $130^{\circ}$ relative to the south facing mirror (Fig. 1). The side mirrors resulted in significant shading of the plot in morning and early evening. As such, following an initial monitoring period of 3 months starting in March 2013, the side mirrors were removed in sequence, leaving only the central south facing mirror. Data were collected for an additional 3 months starting in June 2013 following side mirror removal.

Surface and shallow subsurface soil temperatures were recorded using a 12 bit Temperature Smart Sensor (S-TMBM006) attached to a HOBO Micro Station Data Logger (H21-002; Onset Computer Corporation, Bourne, MA, USA) set to record on a $15 \mathrm{~min}$ interval. The surface thermocouple was placed directly on the soil surface and the shallow subsurface probe was placed $5 \mathrm{~cm}$ below the soil surface. Control thermocouples were placed adjacent to the mirror plot 

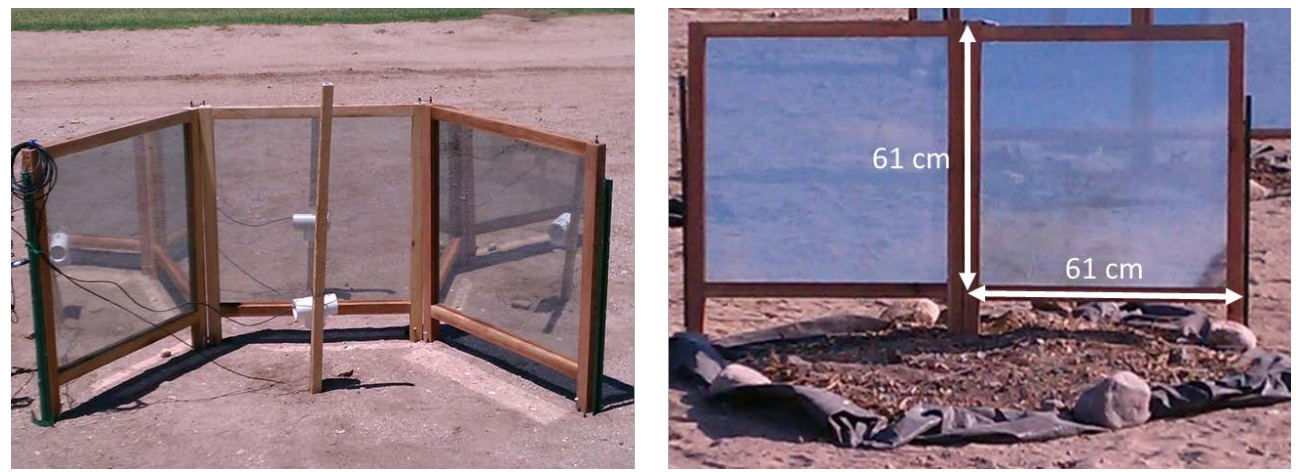

Figure 1. Example of the infrared mirror design showing (a) the initial three-mirror array and (b) the two $61 \times 61 \mathrm{~cm}$ panel design that was implemented for the replicated plot field trial. The photo in (a) was taken at midafternoon with the sun to the west and the photo in (b) was taken at midmorning with the sun to the east; note the shading induced by the mirror frame in both photos.

and linked to the same data logger; roughly $1 \mathrm{~m}$ separated the control and test plots.

\subsubsection{Replicated plots}

The replicated field experiment was also located at the CAC in a field adjacent to the test plot location. The replicated field experiment was part of a larger project examining the role of soil amendments on two different soils on native vegetation establishment in stockpiled topsoil from an open-pit mine. The two soils used in this experiment were collected at $31^{\circ} 50^{\prime} 34.30^{\prime \prime} \mathrm{N}, 110^{\circ} 45^{\prime} 05.96^{\prime \prime} \mathrm{W}, 1615 \mathrm{~m}$ a.s.l., and $31^{\circ} 49^{\prime} 20.48^{\prime \prime} \mathrm{N}, 110^{\circ} 44^{\prime} 03.62^{\prime \prime} \mathrm{W}, 1500 \mathrm{~m}$ a.s.l., and mapped as the Chiricahua and Hathaway soil series, respectively (USDA Web Soil Survey, accessed 2015, http://websoilsurvey.sc.egov.usda.gov/). The Chiricahua soil (CHIR) was derived from a mix of metamorphic rocks and classified as an Ustic Haplargid; the Hathaway soil (HATH) was derived from mixed sedimentary rocks, largely sandstone, and classified as an Aridic Calciustoll (USDA Official Soil Series Descriptions, accessed 2015, https://soilseries.sc. egov.usda.gov/osdname.asp). The soils were excavated mechanically to a depth $1.75 \mathrm{~m}$ below the soil surface and delivered to the CAC. Soils were sieved in the field to remove coarse fragments $>15 \mathrm{~cm}$ in diameter before placement in experimental mesocosms.

The replicated field plots consisted of mesocosms constructed in place at the CAC. The mesocosms were located in an open field and subject to ambient climatic conditions. The mesocosms consisted of square excavations of $0.91 \mathrm{~m}$ side length and excavated to a depth of $30 \mathrm{~cm}$ below the soil surface. The square excavation was lined in porous geotextile fabric that allows for water flow but prevents soil in the mesocosm from mixing with the extant soil. The mesocosms were backfilled with the Chiricahua and Hathaway soil material up to the level of the soil surface (Fig. 1).

The replicated field plot experimental design consisted of a randomized complete block design, with each mesocosm randomly assigned to soil type (either Chiricahua or Hathaway), control (no mirror), and mirror (IR mirrors), with four replicates of each treatment. Plots with IR mirrors were equipped with two adjacent IR mirrors oriented due south, tilted back $10^{\circ}$ from vertical, and secured with metal t posts (Fig. 1). Two mirrors were used to ensure greater coverage of the mesocosm with re-radiated IR energy. It was assumed that the shading effects from the mirror frame were minimal.

The CHIR and HATH soils varied in texture and coarse fraction content, color, and organic matter. Particle size analysis was quantified by laser particle size analysis following removal of organic matter. Weight percent of coarse fragments was quantified as the fraction not passing a $2 \mathrm{~mm}$ sieve. Dry and moist soil color were measured using a Spectron CE-590 spectroradiometer (Spectron Instruments, Denver, $\mathrm{CO}$ ) and converted to Munsell notation, and organic matter quantified as loss on ignition (LOI) following $2 \mathrm{~h}$ combustion at $500^{\circ} \mathrm{C}$. Soil color was used to estimate dry and moist soil albedo $(0.3-2.8 \mu \mathrm{m})(\alpha)$ following Post et al. (2000) as $\alpha=0.069 v-0.114$, where $v$ is the Munsell soil value. The volumetric heat capacity of the different soils in each mesocosm, $C_{T}$, was calculated as (Jury et al., 1991; Kluitenberg, 2002)

$C_{T}=\left(C_{\mathrm{O}} X_{\mathrm{O}}+C_{\mathrm{S}} X_{\mathrm{S}}+C_{\mathrm{R}} X_{\mathrm{R}}\right)\left(1-\phi_{T}\right)$,

where $C_{\mathrm{O}}, C_{\mathrm{S}}$, and $C_{\mathrm{R}}$ are the volumetric heat capacities of organic matter, soil, and rock with values of 2.5, 1.9, and $2.4 \mathrm{~kJ} \mathrm{~kg}^{-1} \mathrm{~K}^{-1}$, respectively (Eppelbaum et al., 2014; Kluitenberg, 2002), $X_{\mathrm{O}}, X_{\mathrm{S}}, X_{\mathrm{R}}$ are the volume fractions organic matter, soil, and rock in the mesocosm, and $\varphi_{T}$ is the total porosity of the mesocosm calculated assuming the volume rock fraction has zero porosity and soil bulk density calculated following Rawls (1983). The values for $C_{T}$ were calculated assuming a zero water content to provide a dry reference volumetric heat capacity for each soil type. These data provide a direct measure of the amount of heat required to warm the soil system, such that for soils of varying heat capacity receiving the same amount of heat energy, the soil 
with a greater heat capacity will record a smaller temperature increase relative to the soil with a lower heat capacity.

Repeated measures of surface soil temperature were recorded with a handheld IR thermometer (Cen-Tech model 60725, Cen-Tech, Camarillo, CA, USA) from a height of approximately $1 \mathrm{~m}$ above the soil surface on six dates between 20 August and 24 September 2013. The IR thermometer was used in the replicated field plots due to the fact that the relatively high number of replicates limited installation of thermocouples and data loggers for all replicate plots. Repeated measures of soil moisture measured were recorded using a FieldScout TDR 100 Soil Moisture Meter (Spectrum Technologies Inc. Plainfield, IL, USA) with $10 \mathrm{~cm}$ probes on 16 dates between 22 August and 15 October 2013.

\subsection{Data manipulation and statistical analyses}

The relative soil heating by the IR mirrors in the initial field trials was calculated as

$\Delta T=T_{\mathrm{IR}}-T_{\mathrm{C}}$,

where $\Delta T$ is the relative increase or decrease in soil temperature, $T_{\mathrm{IR}}$ is temperature in the IR mirror plot, and $T_{\mathrm{C}}$ is temperature in the control plot, both in degrees Celsius. Statistical analyses for the initial field trial included simple summary statistics for $\Delta T$ values and correlation of $\Delta T$ to meteorological variables collected at the nearby AZMET (Arizona Meteorological Network) station.

Statistical analyses for the replicated plot experiment included a summary of soil temperature and moisture by soil type, with means comparison of surface $\Delta T$ and the difference in soil moisture between mirror and control, $\Delta \Theta_{v}$, and treatments by soil type. Prior to statistical analysis, temperature and moisture data for the four replicate plots of mirror and control treatments for each soil type were averaged by date. The relative difference in surface temperature, $\Delta T$, and soil moisture, $\Delta \Theta_{v}$, between mirror and control plots was calculated as the difference between the means for each treatment for each soil type. Significant differences in $\Delta T$ and $\Delta \Theta_{v}$ by soil type were determined on the means of all observation dates using an unequal variance $t$ test. Additionally, $\Delta T$ and $\Delta \Theta_{v}$ were correlated with local meteorological variables from the AZMET station. All statistical analyses were performed using JMP Pro 11.0.0 (SAS Institute, Cary, $\mathrm{NC})$.

\section{Results and Discussion}

\subsection{Initial field trials}

The initial field trial with the three-mirror array yielded substantial warming of the shallow subsurface soil $(5 \mathrm{~cm}$ depth), with maximum midday warming near $17^{\circ} \mathrm{C}$ relative to the unheated control plot (Fig. 2). Heating was greatest between


Figure 2. Contour plot of relative soil heating, $\Delta T\left({ }^{\circ} \mathrm{C}\right)$, by day of year and time of day (a) and daily mean (bold red line) and minimum and maximum (dashed lines) $\Delta T$ by day of year (b). The vertical dashed lines in (a) and (b) represent changes from the threemirror array to the two-mirror array and finally the one-mirror array.

the hours of 11:00 and 13:00 LT when the sun was at its highest point in the sky with a mean $\Delta T$ of $1.1{ }^{\circ} \mathrm{C}$. However, as the year progressed from early spring to summer and the sun moved further to the north, substantial cooling of the mirror plot was observed in the morning and evening hours, with a concurrent reduction in midday heating (Fig. 2). In particular, the afternoon temperature differential indicated the mirror plots were up to $5{ }^{\circ} \mathrm{C}$ cooler at $5 \mathrm{~cm}$ depth than the control plot. The morning and afternoon cooling was due to shading from the side mirrors oriented at $130^{\circ}$ relative to the central south facing mirror.

We conducted several short-term experiments with the three-mirror array to try and address the morning and afternoon shading. The first experiment simply included changing the angle of the side mirrors from 130 to $160^{\circ}$ relative to the central south facing mirror, between days 141 and 154 . Opening the mirrors did reduce the amount of shading and 
Table 1. Summary of $\Delta T$ statistics for the initial set of field trials measuring soil heating resulting from infrared mirrors.

\begin{tabular}{lrrccc}
\hline Treatment & $\begin{array}{r}n^{*} \\
(\mathrm{~h})\end{array}$ & Mean $\Delta T$ & $\begin{array}{c}\text { Minimum } \Delta T \\
\left({ }^{\circ} \mathrm{C}\right)\end{array}$ & Maximum $\Delta T$ & $\begin{array}{c}\text { Fraction Time } \Delta T \geq 0^{\circ} \mathrm{C} \\
(\%)\end{array}$ \\
\hline Three mirrors $-130^{\circ}$ & 1898 & $1.1 \pm 3.6$ & -9.2 & 16.9 & 75 \\
Three mirrors $-160^{\circ}$ & 299 & $-0.2 \pm 2.3$ & -8.2 & 2.9 & 59 \\
Two mirrors & 253 & $0.5 \pm 1.4$ & -5.1 & 3.8 & 70 \\
One mirror & 2320 & $0.3 \pm 0.9$ & -2.6 & 4.5 & 67 \\
\hline
\end{tabular}

* Number of hours measured for each treatment.
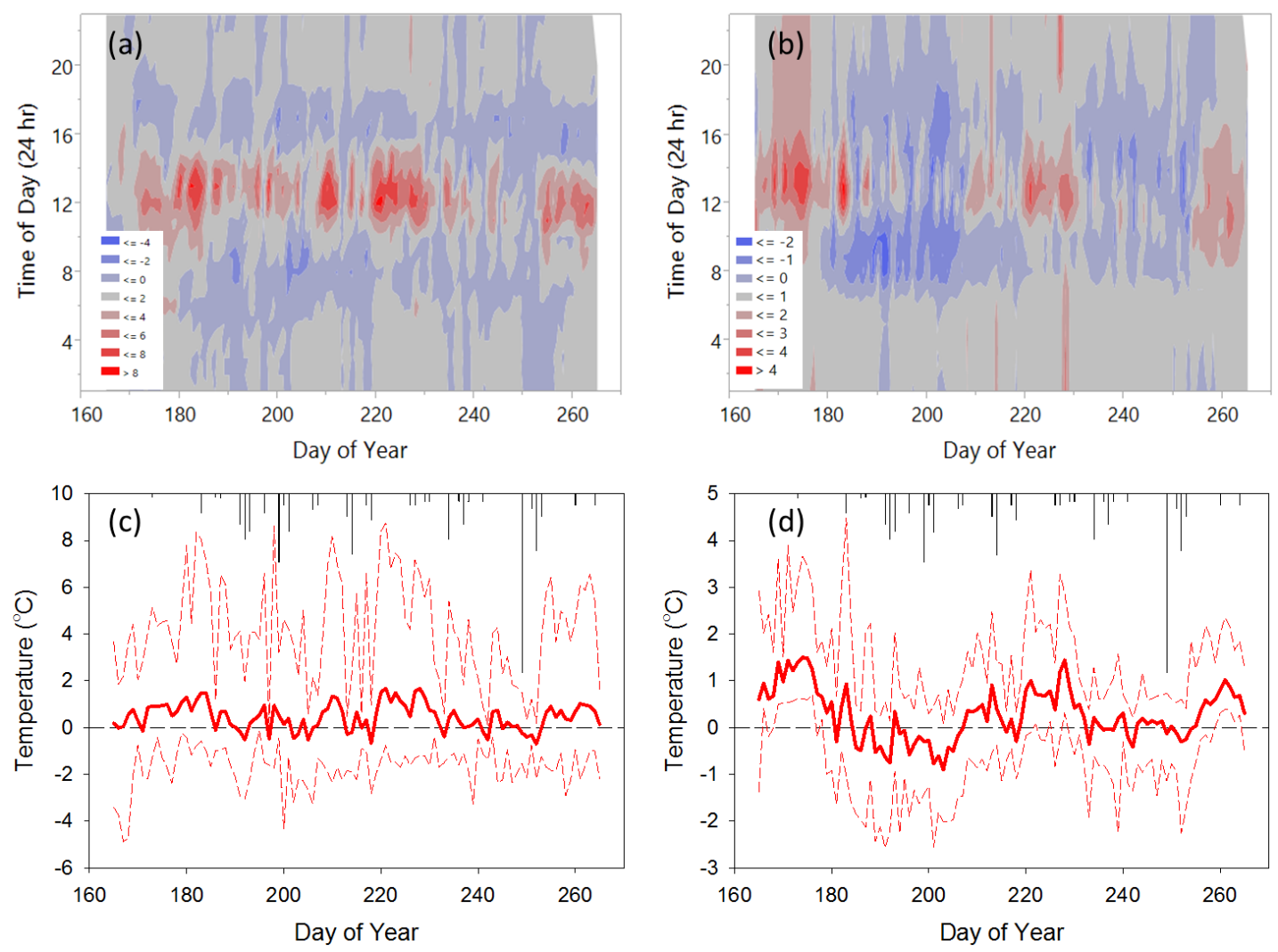

Figure 3. Contour plot of relative soil heating, $\Delta T\left({ }^{\circ} \mathrm{C}\right)$, by day of year and time of day for soil surface (a) and shallow subsurface (5 cm depth) (b) for the one-infrared-mirror array. Daily mean (bold) and minimum and maximum (dashed lines) $\Delta T$ values for the surface (c) and shallow subsurface (d). Black bars on the upper $x$ axis are daily precipitation totals from the nearby meteorological station.

increase the hours of warming but yielded a mean $\Delta T$ value near $-0.2^{\circ} \mathrm{C}$, with brief periods of $4-5^{\circ} \mathrm{C}$ cooling in the afternoon hours (Table 1). The second experiment ran from day 154 to 164 and included removing the west panel to try and eliminate the afternoon cooling trend. This experiment did yield a reduction in both morning and afternoon cooling and returned the mean $\Delta T$ to an overall warming trend of $0.5^{\circ} \mathrm{C}$.

The final field trial experiment consisted of removing both side mirrors, leaving just the one south facing mirror. In this instance, soil temperature was measured both directly at the soil surface and at a $5 \mathrm{~cm}$ depth. The data indicated mean $\Delta T$ values of 0.5 and $0.3{ }^{\circ} \mathrm{C}$ at the surface (Fig. 3a) and $5 \mathrm{~cm}$ depth (Fig. 3b; Table 1). Both surface and $5 \mathrm{~cm}$ depth temperatures exhibited the greatest heating at midday, with maximum $\Delta T$ values near 10 and $5{ }^{\circ} \mathrm{C}$, respectively. Periods of cooling were still evident in the morning and afternoon hours. Detailed observation of diurnal $\Delta T$ trends indicate cooling between the hours of 08:00 and 10:00 that was then overcome by heating during the midday hours. Of the $\sim 2300$ hourly average $\Delta T$ values, 64 and $67 \%$ of observations were $\geq 0{ }^{\circ} \mathrm{C}$ for surface and subsurface soils, respectively, such that the majority of observations indicated warming (Table 1). The majority of hours that indicated cooling exhibited $\Delta T$ values between -1 and $-2{ }^{\circ} \mathrm{C}$, with less than 2 and $0.7 \%$ of surface and subsurface measurements, respectively, recording cooling greater than $-2{ }^{\circ} \mathrm{C}$. 

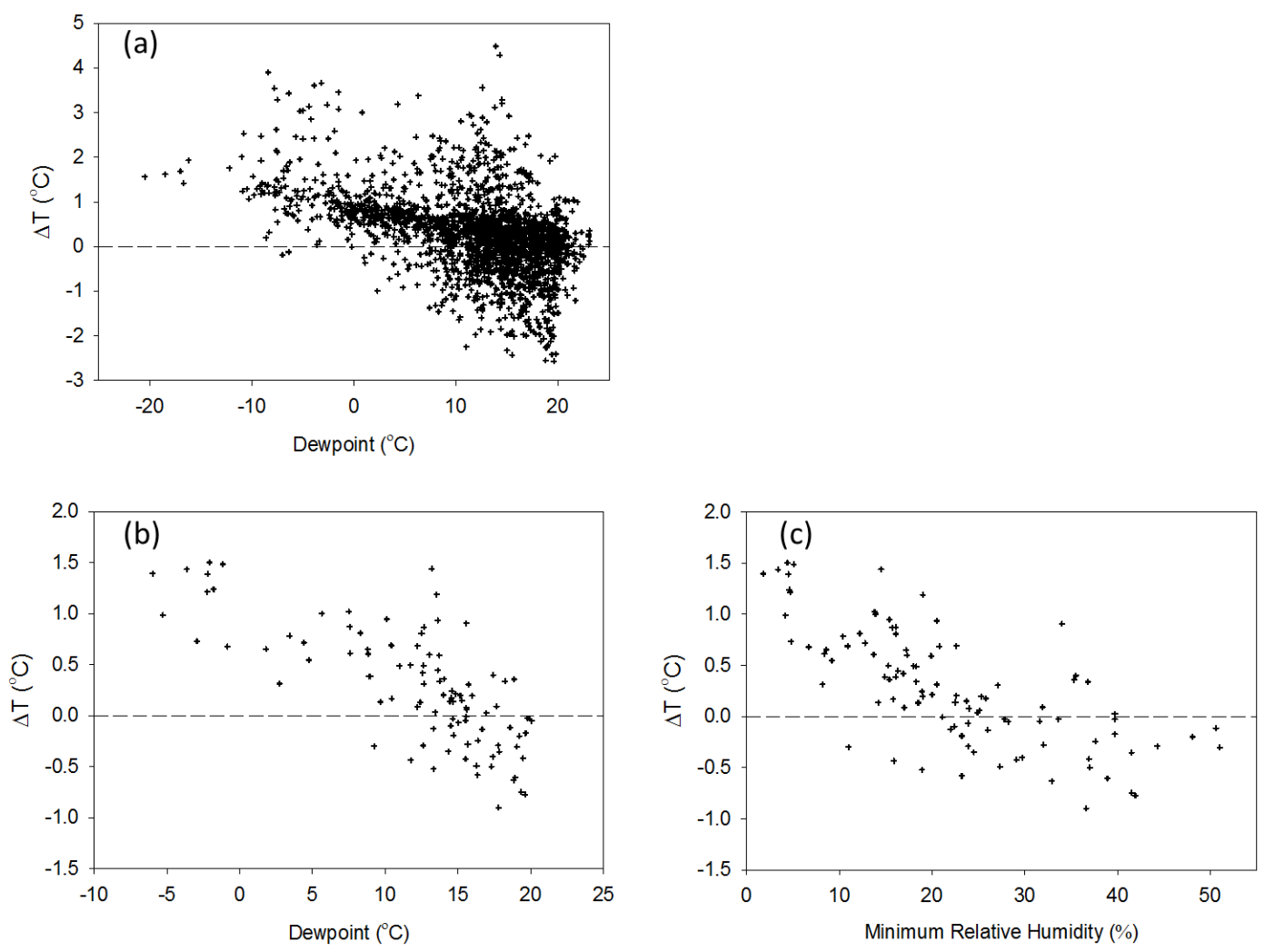

Figure 4. Relative soil heating, $\Delta T\left({ }^{\circ} \mathrm{C}\right)$, compared to dew point $\left({ }^{\circ} \mathrm{C}\right)$ for all hourly measurements from the one-panel array $(\mathbf{a})$. Daily average $\Delta T$ relative to daily average dew point and daily minimum relative humidity (\%). The dashed line on the $y$ axis indicates a $\Delta T$ value of zero with values greater than zero indicating heating and values less than zero indicating cooling as a result of the infrared mirror treatment.

Comparing the one-mirror $\Delta T$ values to meteorological variables indicated that the relative cooling in mirror plots was greatest during periods of high atmospheric moisture and following precipitation events when surface soils were moist (Fig. 4a). This was evidenced by significant negative trends in $\Delta T$ with both mean daily dew point (Fig. 4b) and daily minimum relative humidity (Fig. 4c). Both of these values provide a measure of atmospheric moisture content, with the mean daily dew point as daily average and minimum relative humidity providing a measure of atmospheric humidity at the hottest point in the day. These data clearly indicate that the warming effect of the mirror was minimized or negated with a wet atmosphere. This trend was particularly evident in the $5 \mathrm{~cm}$ depth $\Delta T$ values following rainfall events. Detailed diurnal analysis of $5 \mathrm{~cm} \Delta T$ values indicated that during wet periods following rainfall events the midday heating from the mirror was not enough to overcome any cooling associated with morning and afternoon shading. These data were consistent with both atmospheric and soil moisture limiting temperature increases in the shallow subsurface. Furthermore, the increased energy transfer to the soil in the mirror plot may also have increased evaporation rates that would buffer any warming as energy was consumed via vaporization (e.g.,
Wåhlin et al., 2010). However, soil moisture was not monitored during the initial field trials. These data highlight that the greatest warming impact of mirrors was during periods with dry soil and atmospheric conditions and also suggest the potential for changes in surface soil water balance that would lead to more evaporation and soil drying in the mirror treatments.

\subsection{Replicated plot experiments}

The replicated field plot experiments indicated significant heating of the soil surface with an average $\Delta T$ of $+5.5^{\circ} \mathrm{C}$ (Fig. 5; Table 2). These measurements were single time points collected during the midday time period; as such they represent near maximum temperature differentials based on the continuous data patterns collected in the initial field trial. The relative warming also varied significantly by soil type, with HATH exhibiting $\Delta T$ of $+6.8^{\circ} \mathrm{C}$ and CHIR exhibiting $\Delta T$ values of $+4.1^{\circ} \mathrm{C}$ (Table 2). The CHIR plots contained a larger fraction of rock fragments, lower estimated total plot porosity, and higher heat capacity that would also limit temperature change per unit of additional IR radiation (Jury et al., 1991) (Table 2). 


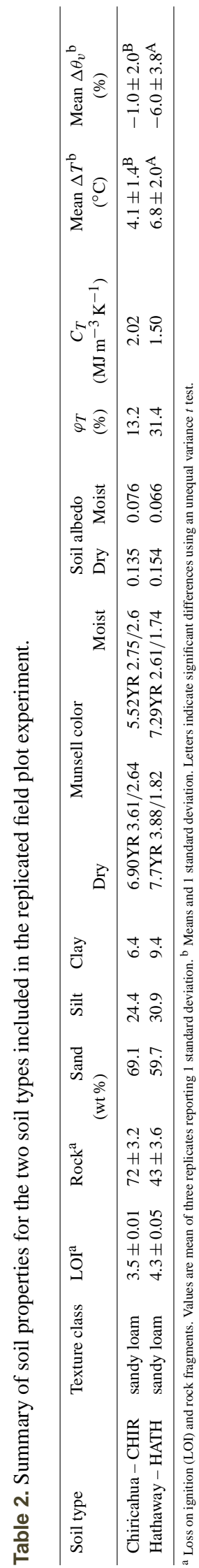

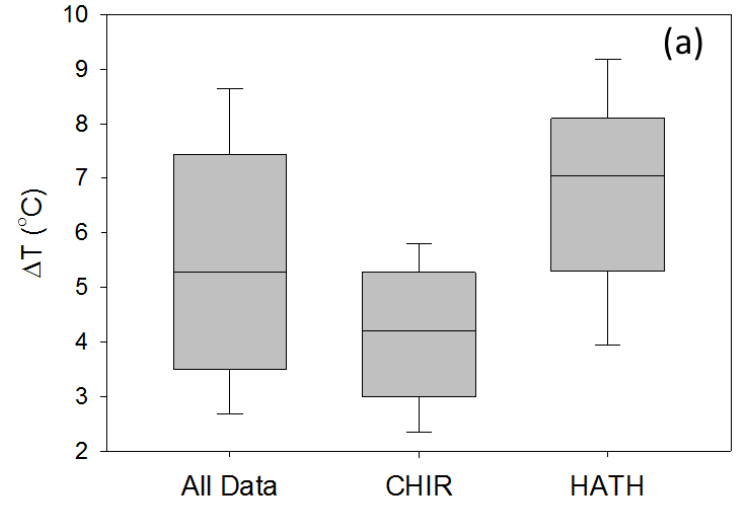

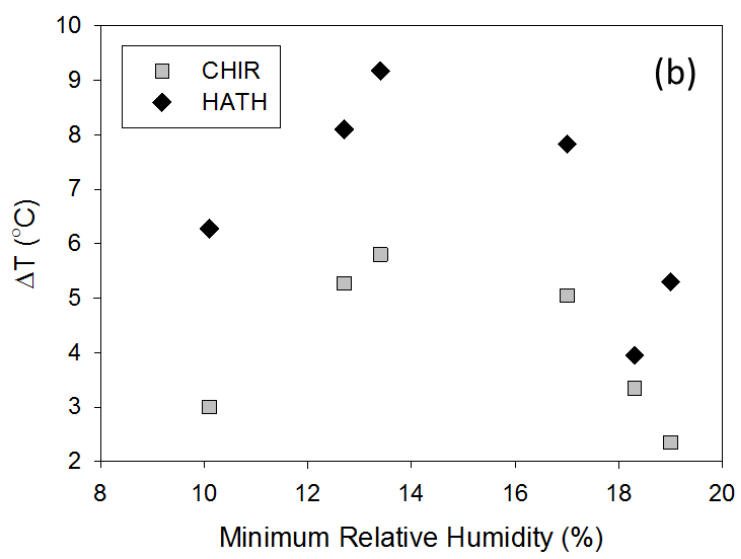

Figure 5. Box plots of relative soil heating, $\Delta T\left({ }^{\circ} \mathrm{C}\right)$, for all data from the replicated field experiment (All Data) and for data separated by soil type (Chiricahua, CHIR, and Hathaway, HATH) (a), and mean daily relative soil heating $\Delta T$ compared to daily minimum relative humidity for the two soil types (b).

The replicated field plot $\Delta T$ values exhibited a general negative trend with increasing minimum daily relative humidity across all sampled dates $(r=-0.32)$ (Fig. 5), confirming the field test trials where warming from the mirrors was attenuated by atmospheric and soil moisture. The date that deviated most substantially from this overall trend was the last date collected on day 267, noted in Fig. 5. This measurement date was preceded by the largest series of rainfall events during the observation period that corresponded to increased soil moisture content in both the CHIR and HATH soils. The lack of differential heating at this time period despite relatively low minimum relative humidity values was thus likely controlled by soil moisture content. Excluding this day, the correlation between $\Delta T$ and minimum daily relative humidity increased and became significant $(r=-0.66$; $P<0.05)$.

Soil moisture data indicated a relative drying trend in the mirror plots, with significantly greater drying in the HATH relative to the CHIR soils (Fig. 6; Table 2). The CHIR soils exhibited high rock fragment content, coarse-textured fine-earth fraction, and only $13 \%$ total mesocosm porosity 
leading to both a limited water holding capacity and faster drainage relative to the HATH mesocosms (Table 2). This was confirmed by soil moisture data from the control mesocosms that indicated CHIR soils averaged $13.6 \%$ volumetric water content relative to $22.7 \%$ in the HATH soils and that for each day of observation, the CHIR soils were drier than the HATH soils by $5-15 \%$ volumetric water content. The CHIR soils also exhibited a greater volumetric heat capacity in the solid phase that would limit the transfer of heat energy to soil water and vaporization. In contrast, the HATH soils exhibited fewer coarse fragments, greater clay and silt content, and greater porosity, indicating greater water holding capacity in addition to a lower volumetric soil heat capacity of the solid fraction. These factors favor warming of the soil and greater transfer of absorbed energy to soil water, favoring soil water vaporization. The drying results are similar to results of Harte et al. (1995) and Verburg et al. (1999), which found significant drying with IR lamps and soil heating cables, respectively.

\subsection{Mirror success, limitations, and future directions}

The results from this proof-of-concept study indicate that the IR mirrors do effectively heat the near soil surface but also highlight a number of limitations and future directions for research to improve mirror implementation in the field.

Mirror successes include that

- the mirrors are inexpensive to construct and can be easily installed in any number of field settings;

- the infrared mirrors yielded significant heating and drying of soil surface and shallow subsurface relative to unwarmed control treatments, with an average soil warming of $4-7{ }^{\circ} \mathrm{C}$, and average decrease in soil moisture by $1-6 \%$, depending on soil heat capacity.

Mirror limitations include

- periods of shading from the wooden frame,

- relatively uncontrolled heating of the soil surface that is sun angle dependent,

- poor constraint on how the mirrors will work in areas with relatively dense understory vegetation,

- unknown potential for scaling to cover larger areas and relatively poor constraint on the actual area heated by the mirror.

Future research directions include

- redesign of the mirror frame to minimize shading. Most shading appeared to derive from the framing at the bottom of the mirror; the shading can be minimized by redesign of the mirror frame, e.g., only framing on the sides of the mirror;

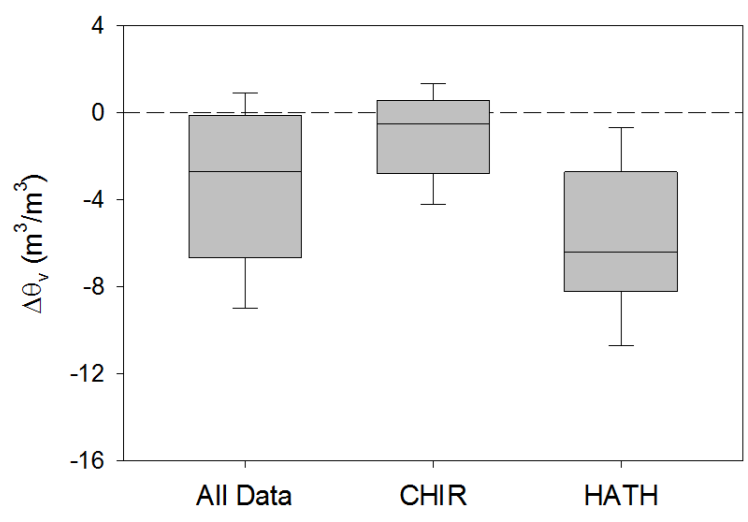

Figure 6. Box plots of relative change in volumetric soil water content, $\Delta \Theta_{v}\left(\mathrm{~m}^{3} \mathrm{~m}^{-3}\right)$, for all for all data from the replicated field experiment (All Data) and for data separated by soil type (Chiricahua, CHIR, and Hathaway, HATH).

- empirical measures of the heated area with an array of thermocouples and possibly an IR camera to measure the exact area heated by the mirror and any temperature gradients that exist at the warming boundaries;

- installation of mirrors in areas with more complete vegetative cover, including both grasses and shrubs/trees, to determine effectiveness for soil warming in vegetated settings;

- numerical modeling that incorporates various mirror sizes, angles, sun angles, latitudes, and cloud cover to optimize mirrors for specific environmental settings.

\section{Conclusions}

The results presented here demonstrate proof of concept that the infrared mirrors tested here may be used to passively heat the near-soil surface, providing an inexpensive, lowmaintenance alternative to other passive and active soil heating technologies. The mirrors as constructed were effective for soil heating in environments typified by open canopy and low canopy vegetation, similar to those present in agriculture systems, desert grassland and scrub ecosystems. Heating from the infrared mirrors significantly impacted both soil warming and drying, similar to trends expected with a warming climate. Key conclusions include that

- the infrared mirrors yielded significant heating and drying of the soil surface and shallow subsurface relative to unwarmed control treatments;

- atmospheric and soil moisture attenuated IR mirrorinduced soil warming;

- the warming and drying effects of the infrared mirrors was soil specific, with greater potential impact on soils with lower volumetric heat capacity. 
It is important to note that the soil warming indicated in initial field trials was more pronounced in winter months when the sun was a lower incidence angle, and that periods of shading related to the frame and mirror orientation were apparent in morning and evening hours. The efficacy of soil heating with the infrared mirrors could be improved with detailed numerical modeling of coupled soil-atmosphere energy and water balances that take into account latitude, seasonal changes in sun position, and soil moisture and heat capacity, e.g., using a model such as HYDRUS 1D. Such modeling would facilitate optimization of mirror angle, size, and orientation to reach the desired experimental soil warming and drying response. Additional modeling coupled with field installation of infrared mirrors in different environments has the potential to make this type of infrared mirror a powerful tool for experimental warming of open canopy and low vegetation canopy systems.

Acknowledgements. This work was funded by a grant from the Rosemont Copper Company. R. E. Gallery acknowledges support from NIFA ARZT-1360540-H12-199 and C. Rasmussen acknowledges NIFA ARZT-1367190-H21-155.

Edited by: B. Rawlins

\section{References}

Aronson, E. L. and McNulty, S. G.: Appropriate experimental ecosystem warming methods by ecosystem, objective, and practicality, Agr. Forest Meteorol., 149, 1791-1799, 2009.

AZMET: The Arizona Meteorological Network, available at: http: //ag.arizona.edu/azmet, last access: 14 September 2015.

Beier, C., Emmett, B., Gundersen, P., Tietema, A., Penuelas, J., Estiarte, M., Gordon, C., Gorissen, A., Llorens, L., Roda, F., and Williams, D.: Novel approaches to study climate change effects on terrestrial ecosystems in the field: Drought and passive nighttime warming, Ecosystems, 7, 583-597, 2004.

Eppelbaum, L. V., Kutasov, I. M., and Pilchin, A.: Applied geothermics, Lecture Notes in Earth System Sciences, Springer-Verlag, Berlin Heidelberg, 751 pp., doi:10.1007/978-3-642-34023-9, 2014.

Hanson, P. J., Childs, K. W., Wullschleger, S. D., Riggs, J. S., Thomas, W. K., Todd, D. E., and Warren, J. M.: A method for experimental heating of intact soil profiles for application to climate change experiments, Global Change Biol., 17, 1083-1096, 2011.
Harte, J., Torn, M. S., Chang, F. R., Feifarek, B., Kinzig, A. P., Shaw, R., and Shen, K.: Global Warming and Soil Microclimate - Results from a Meadow-Warming Experiment, Ecol. Appl., 5, 132-150, 1995.

IPCC: Climate Change 2014: Synthesis Report. Contribution of Working Groups I, II and III to the Fifth Assessment Report of the Intergovernmental Panel on Climate Change. CoreWritingTeam, edited by: Pachauri, R. K., and Meyer, L. A., IPCC, Geneva, Switzerland, 2014.

Jury, W. A., Gardner, W. R., and Gardner, W. H.: Soil physics, J. Wiley, New York, 1991.

Kennedy, A. D.: Simulated Climate-Change - Are Passive Greenhouses a Valid Microcosm for Testing the Biological Effects of Environmental Perturbations, Global Change Biol., 1, 29-42, 1995.

Kluitenberg, G. J.: Heat capacity and specific heat, in: Methods of Soil Analysis. Part 4 - Physical Methods, edited by: Dane, J. H. and Topp, G. C., 5, Soil Science Science of America, Madison, WI, 2002.

Peterjohn, W. T., Melillo, J. M., Bowles, F. P., and Steudler, P. A.: Soil Warming and Trace Gas Fluxes - Experimental-Design and Preliminary Flux Results, Oecologia, 93, 18-24, 1993.

Post, D. F., Fimbres, A., Matthias, A. D., Sano, E. E., Accioly, L., Batchily, A. K., and Ferreira, L. G.: Predicting soil albedo from soil color and spectral reflectance data, Soil Sci. Soc. Am. J., 64, 1027-1034, 2000.

Rawls, W. J.: Estimating Soil Bulk-Density from Particle-Size Analysis and Organic-Matter Content, Soil Science, 135, 123$125,1983$.

Rustad, L. E., Campbell, J. L., Marion, G. M., Norby, R. J., Mitchell, M. J., Hartley, A. E., Cornelissen, J. H. C., Gurevitch, J., and Gcte-News: A meta-analysis of the response of soil respiration, net nitrogen mineralization, and aboveground plant growth to experimental ecosystem warming, Oecologia, 126, 543-562, 2001.

Shaver, G. R., Canadell, J., Chapin, F. S., Gurevitch, J., Harte, J., Henry, G., Ineson, P., Jonasson, S., Melillo, J., Pitelka, L., and Rustad, L.: Global warming and terrestrial ecosystems: A conceptual framework for analysis, Bioscience, 50, 871-882, 2000.

Verburg, P. S. J., Van Loon, W. K. P., and Lukewille, A.: The CLIMEX soil-heating experiment: soil response after 2 years of treatment, Biol. Fertil. Soils, 28, 271-276, 1999.

Wåhlin, A. K., Johansson, A. M., Aas, E., Brostrom, G., Weber, J. E. H., and Grue, J.: Horizontal convection in water heated by infrared radiation and cooled by evaporation: scaling analysis and experimental results, Tellus A, 62, 154-169, 2010. 